\title{
Myths of deep and high stress mining — reality checks with case histories
}

\author{
FT Suorineni University of New South Wales, Australia
}

\begin{abstract}
The theme of this conference is 'deep and high stress mining'. Obviously, mining at depth and in high stress is a current challenge and will continue to be so. Despite the several years of dedication to this subject and its importance, the definition of what is 'deep' and 'high stress' remains a matter of conjecture. Clear understanding of these terms, are fundamental to the design of excavations to achieve the benefits of the knowledge accumulated on the subject over the years. This paper aims at critically examining conditions that constitute high stress and explores what is 'depth' in the mining context. International case histories are used to demonstrate how a misunderstanding of 'depth' and 'high stress' can result in wrong mine layouts and excavation designs. The paper then provides conditions that constitute high stress and deep mining as a guide to mine layouts and the design of excavations to cope with these conditions.
\end{abstract}

Keywords: deep mining, high stress, case histories

\section{Introduction}

Stress is a significant factor in determining the safe and economic extraction of orebodies and, hence, an important consideration in determining mining methods. Stacey and Wesseloo (1998) state that from the point of view of planning of mining operations, the in situ stress field is the most important input parameter for modelling of excavations. Hence, stress is one of the primary input parameters in both numerical/analytical and empirical methods in the analysis of mining and tunnelling excavations to predict potential problems and remedies. The theme of this conference, 'deep and high stress mining', is further confirmation of the importance of stress in mine safety and productivity. Despite the significance of the role of stress and its importance in mining it remains the least understood and one of the most difficult parameters to measure with acceptable accuracy. What also constitutes high stress remains debateable. Indeed, several myths on stress remain. This paper attempts to bring to the fore some of these myths for discussion and action. Attempts are made, with support of case histories, to clarify some of the confusion on stress as used in mining practice.

\subsection{In situ stresses}

The recognition of the important role of stress in mining and tunnelling would have implied a good understanding of this parameter and its reliable measurement. Unfortunately, what constitutes 'high stress' and what is meant by 'depth' remains both controversial, and confusing in the literature. Amadei and Stephansson (1997) present an excellent summary of in situ stress measurement techniques. Unfortunately these stress measurement techniques produce results with unacceptable scatter.

Based on experiences at the Underground Research Laboratory in Canada, Martin et al. (2001) conclude that strain-relief stress measurement results become difficult to interpret when the major principal stress $\left(\sigma_{1}\right)$ to intact rock compressive strength $\left(\sigma_{c}\right)$ is between 0.2 and $0.3(1,000$ to $1,500 \mathrm{~m})$ and that, when this ratio exceeds 0.3 the stress measurement results are basically useless. The stress measurement technique can therefore be useless in weaker rocks even at shallow depths. Equally limited in application are the hydraulic stress measurement techniques. Martin et al. (2001) stated that these methods are inefficient in reverse faulting stress environments and that at depths greater than 1,000 m most hydraulic fracturing equipment have less capacities in fracturing rocks for stress measurements. 
Martin et al. (2001) note that predicting in situ stress magnitudes from a stress database is fraught with difficulties. These authors observed that for example, the maximum stress magnitude at a depth of 2,500 $\mathrm{m}$ in the Canadian Shield can range from 50 to $>100 \mathrm{MPa}$, depending on the method of prediction and therefore projecting stress magnitudes at depth is not straight forward. Hoek (1994) lamented that techniques for measuring in situ stress, while greatly improved from what they were, still give an amount of scatter which would be unacceptable in almost any other branch of engineering. This problem is confirmed by Grabinsky et al. (1997) when they noted that even in the most homogeneous geomechanical domains, the stress magnitude can vary by \pm 15 to $\pm 30 \%$ about the component's mean value and the direction can vary by \pm 15 to $\pm 30^{\circ}$ about the mean orientation. Since Hoek's (1994) statement, we still have no better or reliable method for measuring in situ stresses, neither have we developed any better in situ stress measurements data interpretation tools to limit the errors encountered to make them acceptable.

Lee et al. (2014) provide results and details of stress measurements at the Ok Tedi open pit mine in Papua New Guinea (PNG). Results of the various stress measurement campaigns are summarised in Table 1 for three different stress measurement methods, namely: the Commonwealth Scientific and Industrial Research Organisation (CSIRO) hydraulic fracturing (HF) method, Strata Control Technologies (SCT) Australia New Zealand Inflatable (ANZI) overcoring (OC) method and Western Australia School of Mines (WASM) acoustic emission (AE) method at various times. Locations of the stress measurement points are shown in Figure 1.

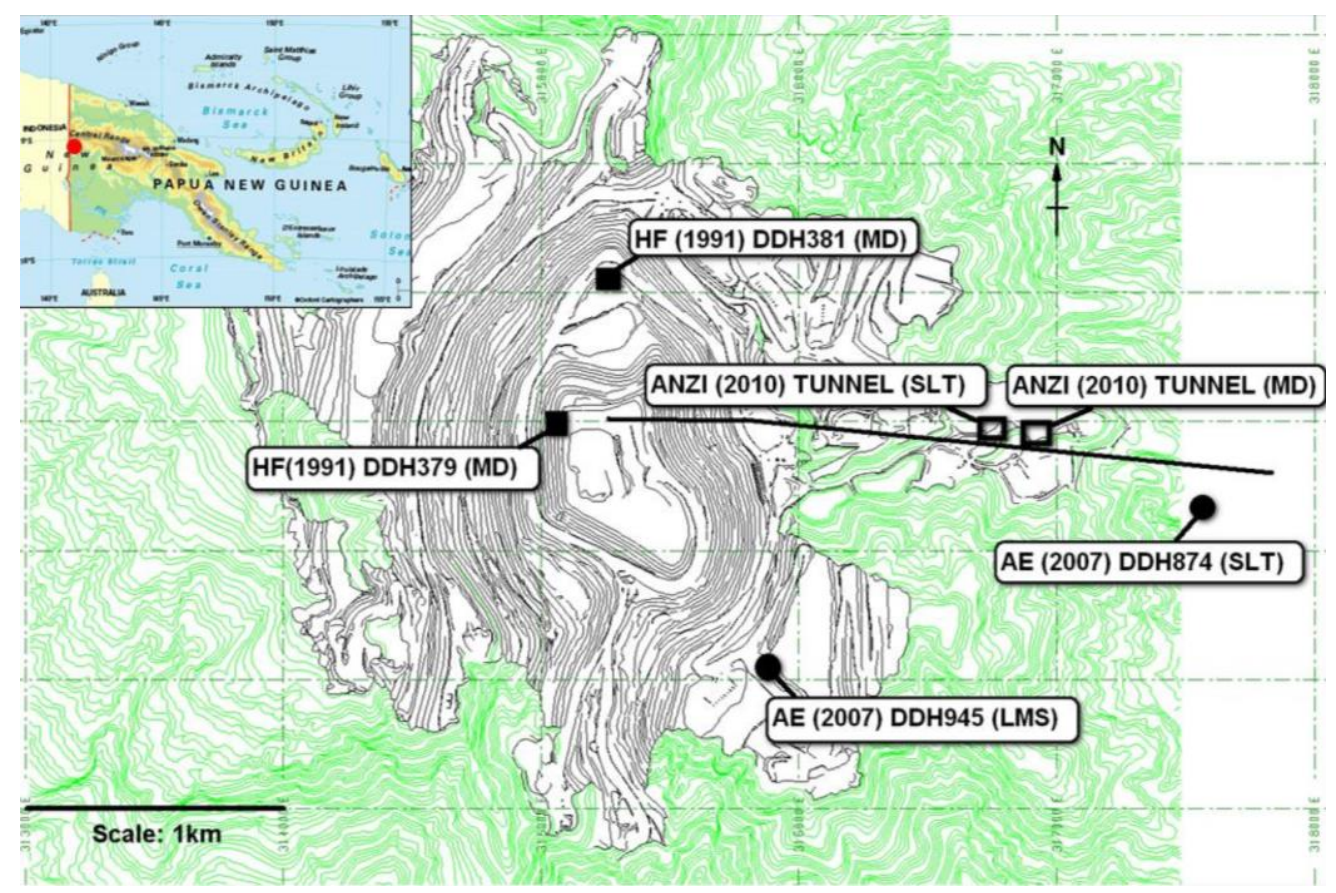

Figure 1 Stress measurement locations at the Ok Tedi open pit site (Lee et al. 2014)

In Table 1, the orientation of the major principal stress $\left(\sigma_{1}\right)$ varies from being horizontal to vertical, while the $K_{0}$-ratio varies from one to three. Similar trends can be seen for the intermediate and minor principal stresses $\left(\sigma_{2}\right)$ and $\left(\sigma_{3}\right)$ respectively. While the differences in results could be due to the complexity of the site geology, the data demonstrate how stress measurement results can cause headaches to the design engineer as he has to decide what input stresses should be used in his numerical model. Lee et al. (2014) admit that the variability of the measured Ok Tedi stresses leads to confusion, frustration and wondering to design engineers. Unfortunately, the Ok Tedi case is not uncommon.

As shown in Figure 2, the frequency of in situ stress measurements continues to decrease (exponential decay function) as depth increases, which may imply an increase in difficulty in the successful use of current stress measurement techniques as depth goes beyond about $1,500 \mathrm{~m}$. This may also mean mining companies are becoming less enthusiastic in in situ stress measurements. There also appear to be less specialists in in situ stress measurements. 
Table 1 Summary of in situ stress measurement methods at Ok Tedi (Lee et al. 2014 from Suorineni 2015)

\begin{tabular}{llll}
\hline Stress model & $\sigma_{1}$ & $\sigma_{2}$ & $\sigma_{3}$ \\
\hline Lee (2011) & 1.3 (north-south) & 1 (vertical) & 0.7 (east-west) \\
Mills (2010) & 1.7 (north-south) & 1 (vertical) & 0.5 (east-west) \\
$\begin{array}{l}\text { Villaescusa and } \\
\text { Machuca (2007) }\end{array}$ & $3^{\text {a } \text { (north-south) }}$ & $2^{\text {a } \text { (east-west) }}$ & 1 (north-south) \\
Power et al. (1991) & 1 (vertical) & 0.4 (north-south) & 0.4 (east-west) \\
\hline
\end{tabular}

a Simplified from initial calculated values.

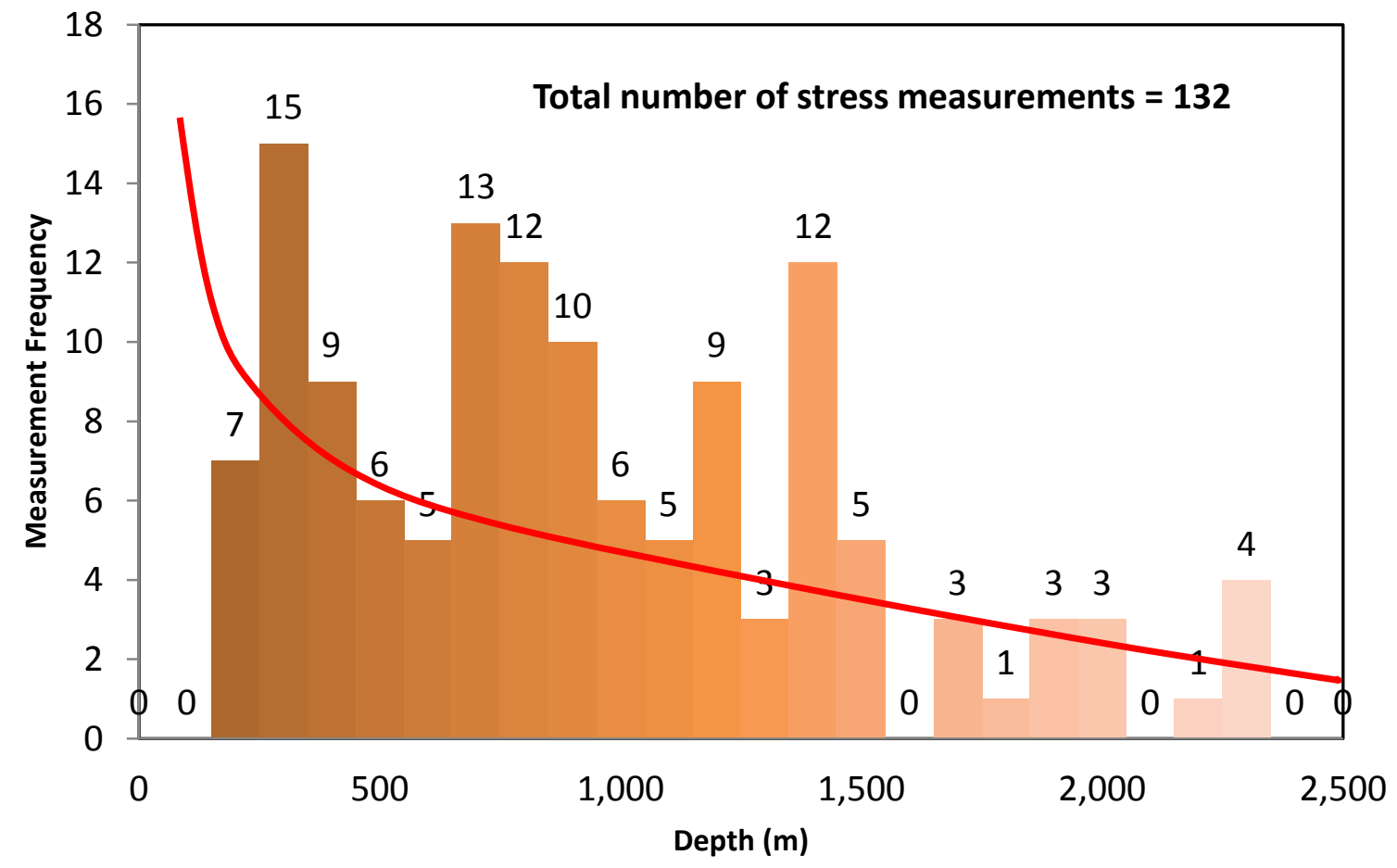

Figure 2 In situ stress measurement frequency exponential decay with depth (modified after Martin et al. 2001)

The above experiences have often resulted in the use of assumed in situ stress states in mine planning and design. Unfortunately, two case studies have shown that these assumptions cannot always be substantiated and therefore making the outputs of such modelling results problematic. Suorineni and Malek (2014) showed that the popularly referred to Sudbury Basin stress tensor source cannot be traced and hence brings its reliability into question. Similarly, Stacey and Wesseloo (1998) noted that the assumption of a horizontal to vertical stress ratio of 0.5 that was commonly made for mining layout analyses in South Africa is generally not valid. The implication is that the use of a $K_{o}$-ratio of 0.5 instead of $K_{o} \geq 1$ in mine layout design would have always resulted in wrong designs. No doubt, several case histories exist (see Martin 1997; Suorineni 2013) in which numerical modelling often predict stability while the actual excavation performance observed show the opposite. These case histories seem to suggest that stress measurements, though erratic are valid endeavours and probably preferred to assumptions that cannot be justified.

\subsection{Depth}

The word 'depth' in geomechanics seems to be used synonymously with 'stress' with the implication that the greater the depth, the higher the stress and vice versa. However, what constitutes shallow depth and great depth or ultra-deep (the two extremes) remains as controversial and confusing as 'what is high stress'. In 
particular, the limiting boundaries between these two extremes are different in, for example, what is implied in coal (or soft rock) mining and hard rock mining. There are two more important misleading implications. First, using increasing depth synonymously as stress, while valid, gives the false impression that vertical stress $\left(\sigma_{v}\right)$ is always the highest of the three principal stresses as implied in the Terzaghi and Richart (1952) equation (see Equation (1)). Second, it implies that high stress conditions cannot be experienced at shallow depth. Turner and Beck (2002) report that in Western Australia stress-related fracturing around mining excavations starts becoming apparent below $300 \mathrm{~m}$ in weaker rocks and below $600 \mathrm{~m}$ in strong rocks. In some underground hard rock mines in Western Australia where rock intact rock strengths range between 100 and $150 \mathrm{MPa}$ (strong to very strong rocks) seismicity is experienced at depths even as shallow as $250 \mathrm{~m}$.

This implication is countered by the fact that in both Scandinavia and Canada, for example, $K_{o}$-ratio expressed as $\sigma_{H} / \sigma_{v}$ or $\sigma_{1} / \sigma_{3}\left(\right.$ for $\sigma_{H}=\sigma_{1}$ and $\sigma_{v}=\sigma_{3}$ ) can be greater than three near surface (Figure 3).

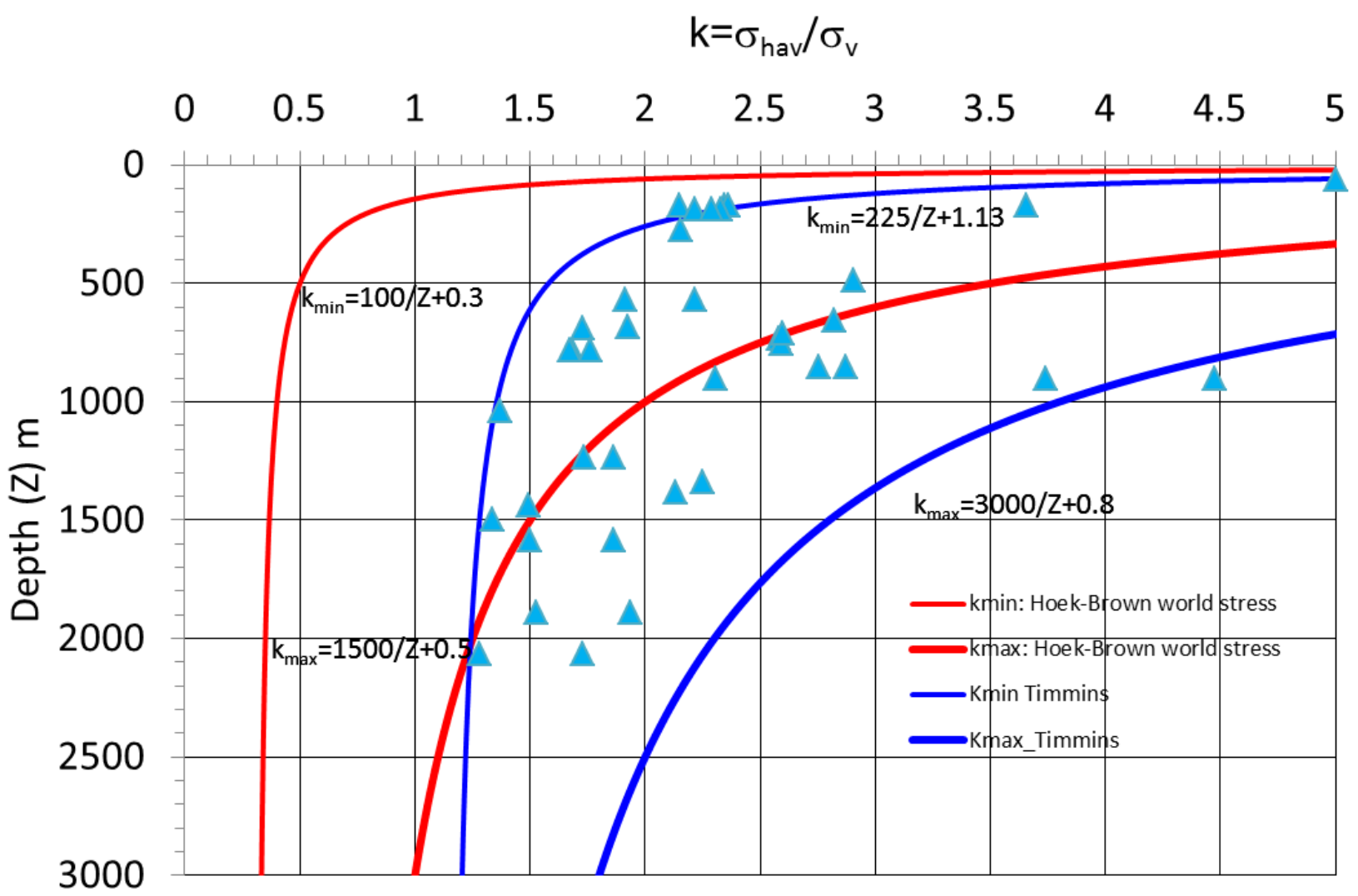

Figure 3 k-variation with depth showing higher horizontal than vertical stresses (Suorineni \& Maloney 2009)

Using depth to imply high stress can be misleading since this premise ignores high stresses created through operational practices such as when drifting through a sill between two levels, mining towards a fault or excavating in a diminishing pillar created by two converging mining fronts (Figure 4). Thus, operational practices can create high stress conditions at 'shallow' depth. 


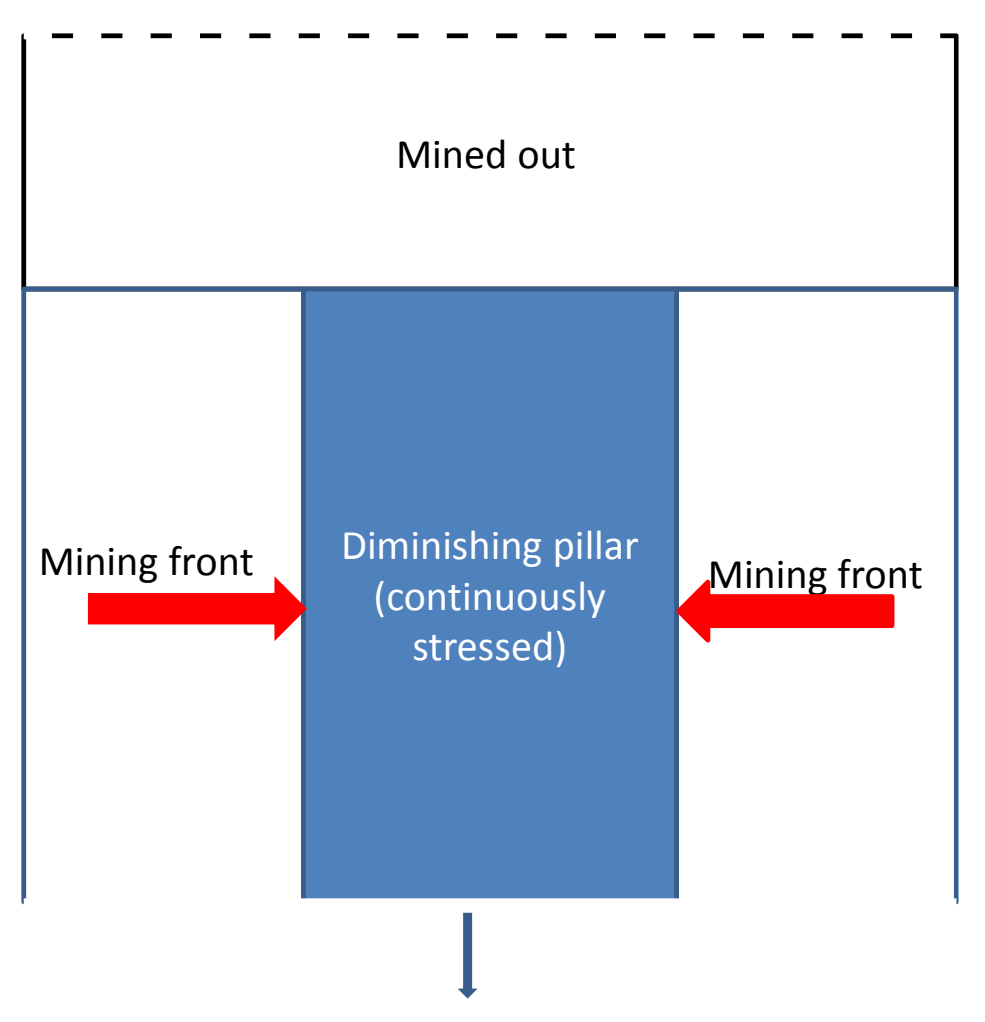

Future development

Figure 4 Schematic of two approaching mining fronts creating a diminishing pillar that is subjected to high stress

The source of the problems discussed above may be traced to the Terzaghi and Richart equation (Equation (1)) (Terzaghi \& Richart 1952):

$$
\sigma_{h}=\frac{v}{1-v} \sigma_{v}
$$

where:

$v$ is Poisson's ratio.

$\sigma_{\mathrm{h}}$ and $\sigma_{\mathrm{v}}$ are the horizontal and vertical stresses respectively.

Poissons' ratio for rocks is on average 0.25 and generally less than 0.5. Hence, in Equation (1), the term $[v /(1-v)]$ is always less than one and is independent of depth. Thus, Equation (1) implies that the horizontal stress is always some fraction of the vertical stress. Stress measurements (Figure 3 ) have shown that this is seldom true and the reverse is generally correct.

Luppens et al. (2009) state that, the depth of coal beds is an important factor affecting coal recovery economics, especially for surface-minable resources. Stripping ratio governs the economics of near-surface mining and determines the limit between surface and underground mining. The implication of stripping ratio is that it will define the economic depth between surface and underground mining depending on coal bed thickness and hence will be variable. According to Luppens et al. (2009) the cross-over depth for mining methods is regionally dependent.

Depth significantly affects both coal recoverability and underground mining economics. With increasing depth, a number of logistical and geotechnical concerns including access and haul distances, roof and floor stability (increased rock pressures), temperature, and groundwater issues become increasingly problematic, leading to substantial productivity declines and economic penalties. The current depth limit to underground coal mining is usually considered to be between 914 and 1,219 m) (Fettweis 1979). The stripping ratio factor 
and significance also holds true for determining when surface mining must change to underground mining in the extraction of metalliferous orebodies. In South Africa, mining is continuing beyond $4 \mathrm{~km}$ below surface at the Mponeng Gold Mine of AngloGold Ashanti. In general, underground mining in hard rocks takes place at greater depths compared to coal. This difference originates from the genesis of the two materials and their competency/strength as well as the strength of their host rocks.

Table 2, while it might appear contradictory to the premise of the paper, provides an intuitive ranking of depth as deciphered from the literature. The table is only provided as a crude guide to the use of depth to reflect mining problems and to, at least, provide some basis for classifying depth. It is also intended to reflect the fact that what might be great depth in coal mining literature, is not the same in hard rock mining.

Table 2 Depth ranking/description based on anticipated hard rock mining issues

\begin{tabular}{|c|c|c|c|}
\hline Category & Depth & $\begin{array}{l}\text { Ranking } \\
\text { description }\end{array}$ & Comment \\
\hline 1 & $<500 \mathrm{~m}$ & Very shallow & $\begin{array}{l}\text { Structurally-induced failures may be dominant in hard } \\
\text { rock. }\end{array}$ \\
\hline 2 & $500-1,000 \mathrm{~m}$ & Shallow & $\begin{array}{l}\text { Some open pits are this deep. Modified material } \\
\text { states (Section } 3 \text { ) from operational practices can cause } \\
\text { stress problems at this depth in underground mines. }\end{array}$ \\
\hline 3 & $1,000-1,500 \mathrm{~m}$ & $\begin{array}{l}\text { Intermediate/ } \\
\text { moderate }\end{array}$ & $\begin{array}{l}\text { Generally minor problems but ground may start } \\
\text { working and modified material conditions from } \\
\text { operational practices could cause significant } \\
\text { problems. Maximum depth of coal mining in this } \\
\text { range. For coal 1,500 m may be mega-depth. Stress } \\
\text { measurement problems start. Martin (1997) gives } \\
1,500 \mathrm{~m} \text { as a limit in the Canadian Shield for } \\
\text { intermediate stress. }\end{array}$ \\
\hline 4 & $1,500-3,000 \mathrm{~m}$ & Deep & $\begin{array}{l}\text { Significant stress problems. Stress measurements a } \\
\text { major challenge. }\end{array}$ \\
\hline 5 & $3,000-4,000 \mathrm{~m}$ & Ultra-deep & Logistics and stability problems a major challenge. \\
\hline 6 & $>4,000 \mathrm{~m}$ & Mega-depth & $\begin{array}{l}\text { Term from Diering (2000) - little experience from this } \\
\text { depth - unchartered waters. }\end{array}$ \\
\hline
\end{tabular}

A fundamental question that arises is whether the economic mining depth is the same as the geotechnical implication of depth when stability problems threaten safety and economics. The answer to this question may be the affirmative. This paper focuses on the geotechnical definition of depth as related to stress and stability issues in hard rock mining.

\subsection{Rock strength}

High stress is not independent of rock strength. There is however confusion with respect to rock strength boundary definitions as shown in Figure 5. Of interest in Figure 5 is the definition of strong or hard rock, since these are the types of rocks of interest at this conference. 


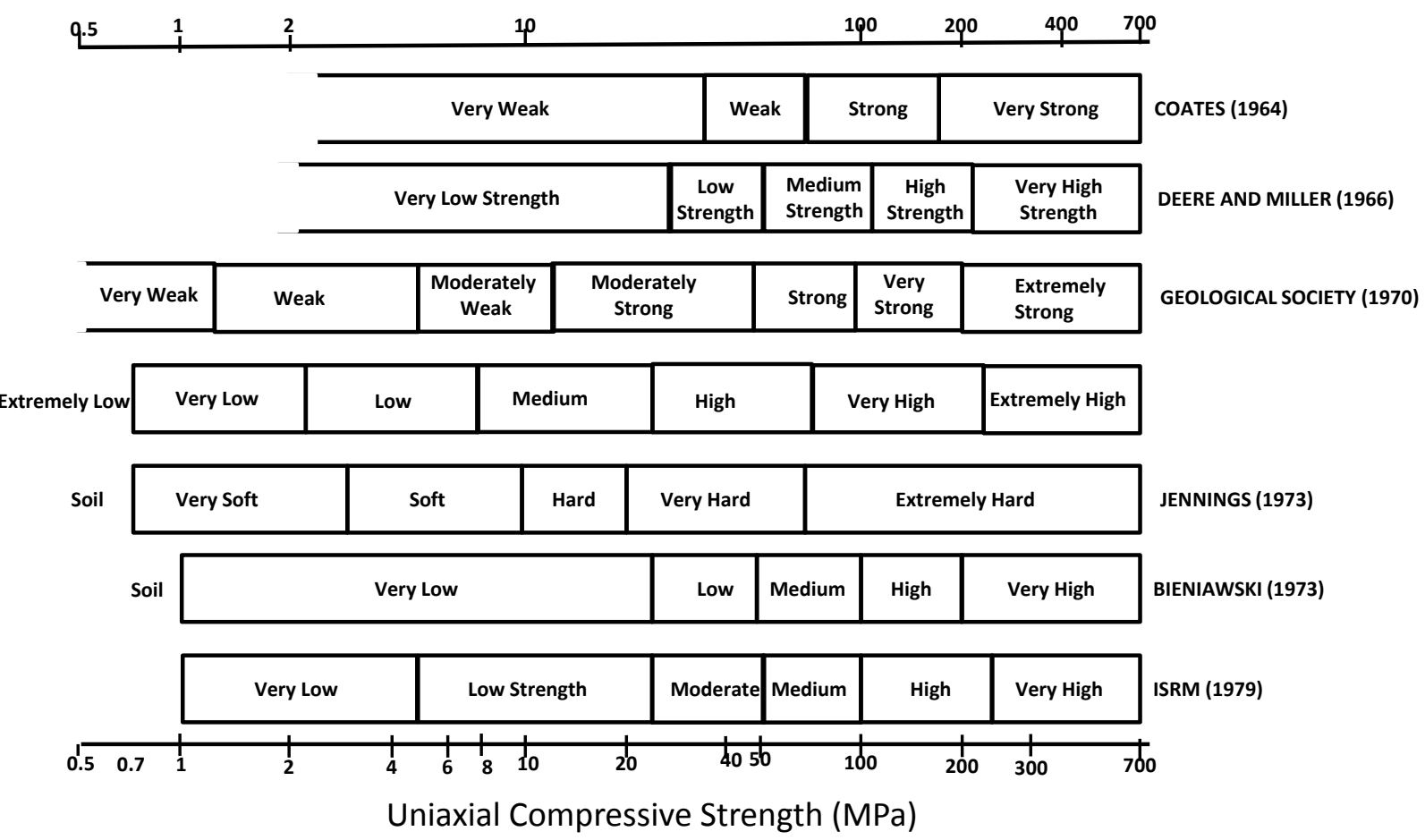

Figure 5 Various strength classifications for intact rock (modified from Bieniawski 1989)

While a strong hard brittle rock may be defined as a rock with uniaxial compressive strength (UCS) (or $\sigma_{c}$ ) of about $100 \mathrm{MPa}$ and a maximum axial strain of between 1 to 5\% (Hawkes \& Mellor 1970), in the coal mining circles a rock with a UCS of 40 to $50 \mathrm{MPa}$ is strong rock.

\section{$2 \quad$ High stress}

As argued above, high stress definition cannot be based on depth, i.e. the vertical principal stress magnitude. High stress can be induced by mining or excavation/operational practices and can occur at shallow depths. This experience is well-supported by rockburst occurrence in many shallow underground mines and in some deep underground mines at relatively shallow levels. White (1946) reports rockbursts in the granite quarries in Barry, Vermont. Similarly, Winkler (1975) reports several cases of rockbursts in quarries in the United States. The incidents of rockbursts in quarries are related to large horizontal stresses relative to vertical stresses at or near surfaces. Coates (1964) wrote: "In a quarry near Marmora, Ontario, the removal of $15 \mathrm{~m}$ of Paleozoic limestone caused an anticlinal buckling of the quarry floor $2.5 \mathrm{~m}$ high and over $100 \mathrm{~m}$ long; horizontal stresses of over about 14 MPa are inferred. Tunnel squeeze in the Niagara area and rockbursts in northern Ontario mines may also be related to high horizontal stresses." The cases cited here indicates the significant role of horizontal stresses, and shows the reference to depth as synonymous to stress, and hence implying great depths means more trouble while shallow depth implies less problems, is grossly misleading.

Intuitively, the definition and characterisation of high stress should be relative to the rock mass quality and intact rock compressive strength. In general, this is often related to intact rock strength of the rock mass for simplicity. This characterisation is more valid based on the arguments above. Figure 5 presents a chart characterising stress levels based on in situ major principal stress and maximum induced tangential stress levels and intact rock uniaxial compressive strength relative to rock mass quality using Rock Mass Rating (RMR) (Bieniawski 1989). According to Figure 6, assuming a depth of $1,000 \mathrm{~m}$ below surface where the measured in situ major principal stress is $27 \mathrm{MPa}$, a rock with $\sigma_{c}=50 \mathrm{MPa}$ will be highly stressed while a rock with $\sigma_{c}=200 \mathrm{MPa}$ will be in low stress conditions. Hence, depth alone does not define high stress. 


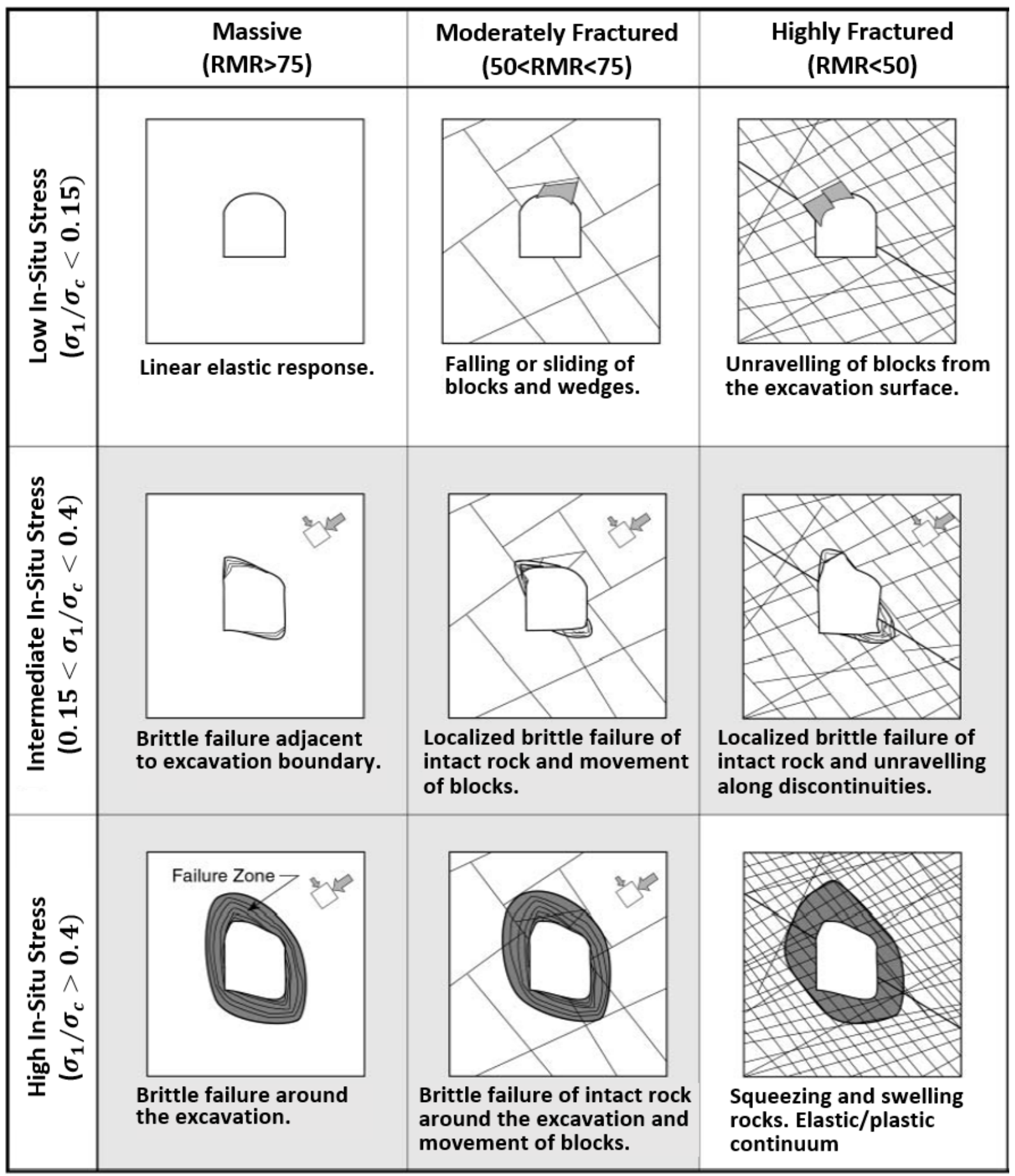

Figure 6 Stress level characterisation with respect to in situ major principal stress and maximum induced tangential stress $\left(\sigma_{\max }\right)$ relative to intact rock uniaxial compressive strength $\left(\sigma_{c}\right)$. Index $D_{i}$ is defined as the ratio of maximum tangential stress on the boundary of the excavation to the intact rock uniaxial compressive strength $\sigma_{c}$ (from Martin et al. 2001)

Swan et al. (2005) used the ratio of major principal stress (in terms of depth) to intact rock uniaxial compressive strength, to characterise well-known underground mines around the world (Figure 7). The figure shows that depths at which various mines can be characterised as deep and high stress vary significantly and therefore supports the argument that depth alone is not sufficient in defining stress conditions. Figure 7 shows such depths vary between $750 \mathrm{~m}$ at Northparkes Mines to about 4,000 m in South Africa for mines in the quartzite. However, the problem with Figure 7 is that it implicitly assumes the vertical stress is the major principal stress, which as shown above is incorrect. 


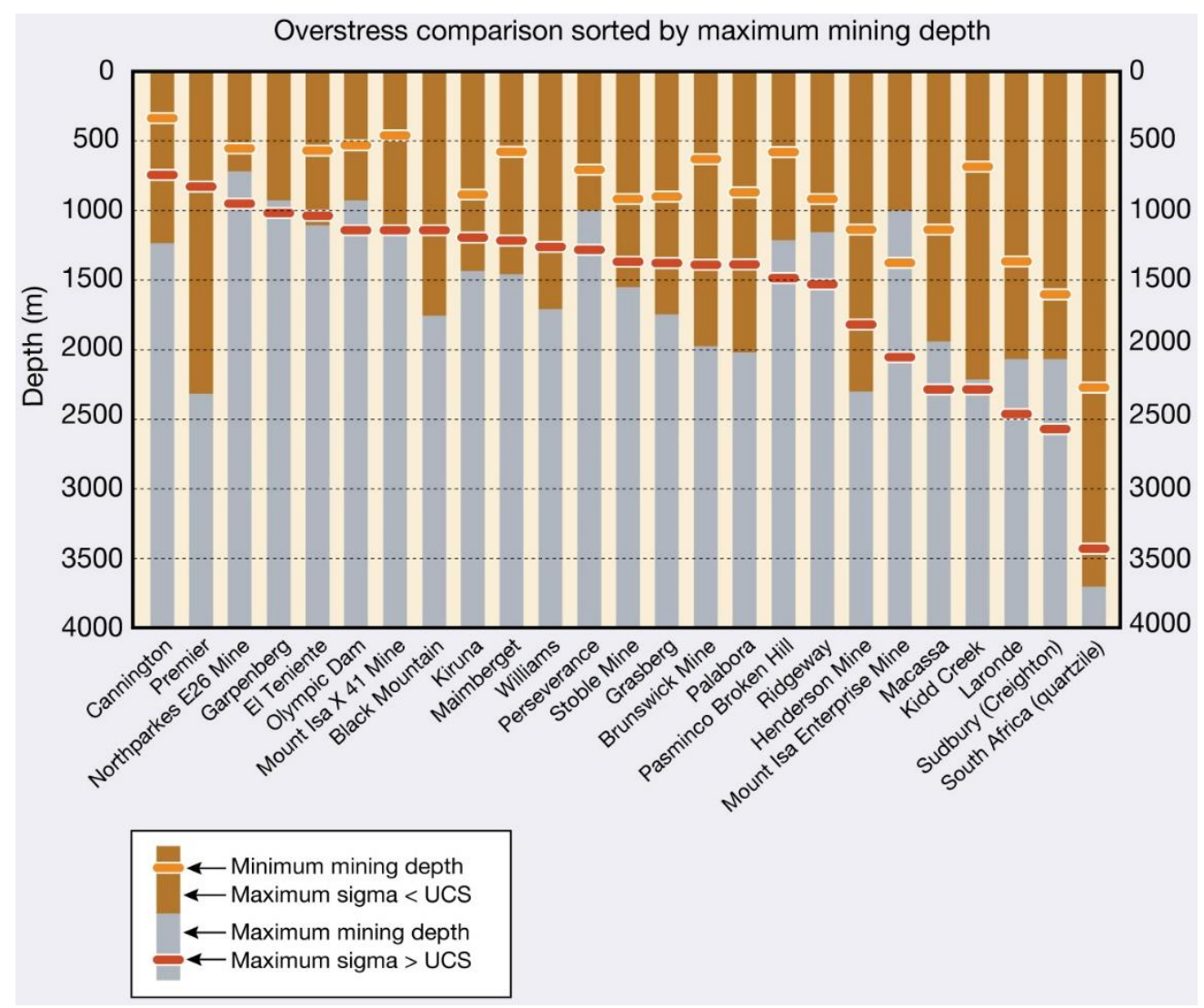

Figure 7 Comparison of 'mining depths' relative to 'overstress depth' where rock will immediately fail around an excavation in virgin stress conditions (Swan et al. 2005)

\section{Change of state in rock}

In material science and engineering, while the concept of brittle to ductile transition is well-understood, the reverse phenomenon of ductile to brittle is rarely debated and more so in geo-engineering. A drop in temperature can cause steel to change behaviour from ductile to brittle and result in an expected brittle failure. The transition temperature for steel to change from ductile to brittle behaviour depends on the composition of the steel.

Several cases are reported throughout history where catastrophic failures occurred as a result of brittle fracture of otherwise ductile materials due to their behavioural changes. The most infamous of these is the sinking of the Titanic in which it is concluded the steel changed from being ductile to brittle as a result of the subzero temperatures encountered.

An overlooked condition that can result in high stress conditions and seismicity at unexpected depths and in materials that would otherwise not be considered seismically-prone because of their ability to continuously dissipate energy, is mining practices that can result in change in material state and behaviour. Some scenarios are presented in the following sections to demonstrate the impact of operational practices on rock state and behaviour.

\subsection{Shear loading}

Suorineni et al. $(2011,2014)$ showed that shear loaded orebodies are at elevated risk during mining compared to their counterparts that have the major principal stress perpendicular to strike. These studies determined that the reason for shear loaded pillars being weaker and at elevated risk of failure (static and dynamic) compared to their counterparts of the identical size but with loading parallel to their long axis is because shear loaded pillars lose confinement in the core. They established that the higher the angle of inclination (dip of orebody) and hence pillar inclination, the more the confinement loss. Confinement loss 
increases brittleness and weakens inclined pillars thereby making them prone to catastrophic failures as observed in the case histories presented by Suorineni et al. (2011). The loss of confinement with increasing pillar inclination is one example of change of state of rock material that results in high stress pillar behaviour at relatively shallow depths. This phenomenon is proven with case histories in Suorineni et al. (2011) and numerical modelling in Suorineni et al. (2014) (Figure 8). It is also recently recognised by Zingano (2016) as being cause of violent pillar failures at a coal mine in Brazil.

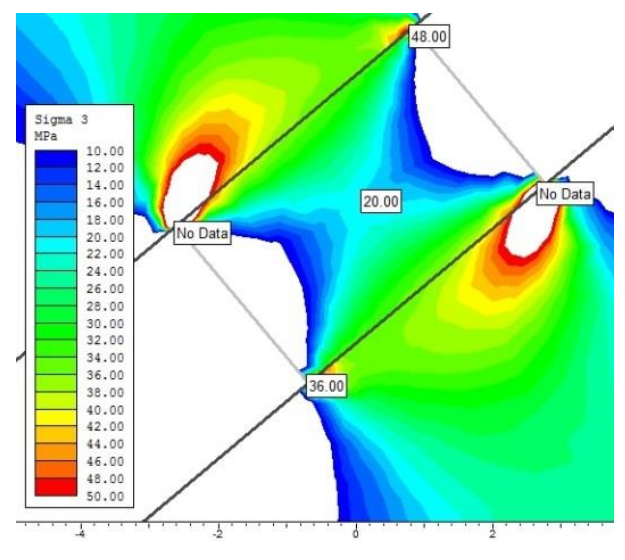

(a) Confinement in core of inclined pillar

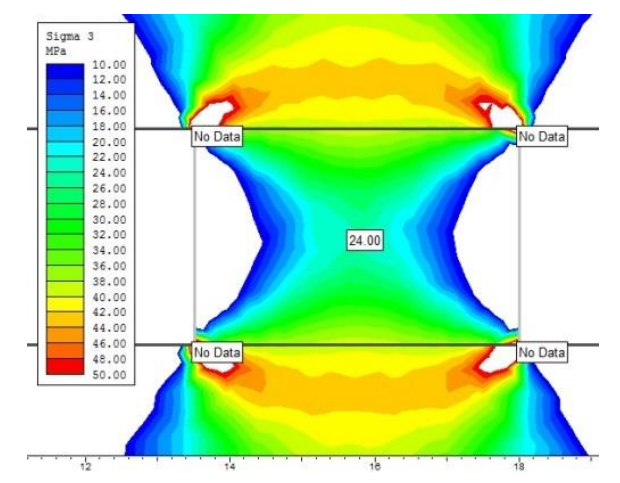

(c) Confinement in core of vertical pillar

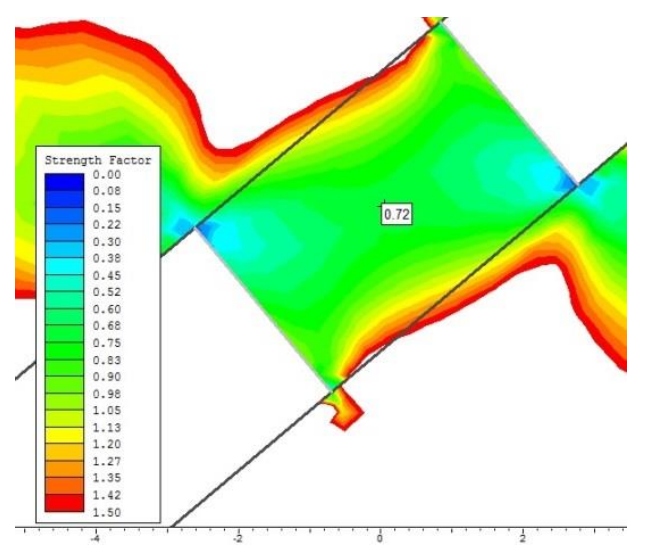

(b) Factor of safety at core of inclined pillar

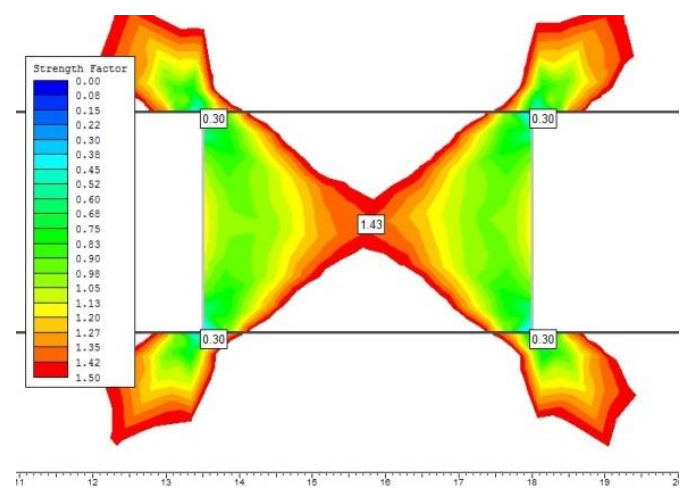

(d) Factor of safety in core of vertical pillar

Figure 8 Comparison of numerical modelling results for inclined/dipping and vertical pillars subjected to same in-situ stresses and having the same rock properties: (a) showing reduced confinement; (b) Factor of Safety in inclined pillar; (c) confinement in core of vertical pillar; and (d) Factor of Safety at core of vertical pillar (from Suorineni et al. 2014).

While the loss in confinement of $4 \mathrm{MPa}$ could be considered small, this may be significant in suppressing stress-induced fracturing. Read et al. (1997) showed at the Underground Research Laboratory (URL) construction that less than $20 \mathrm{kPa}$ is enough to suppress stress-induced damage. They concluded that insignificant notch on the floor of a tunnel compared to the roof or back due to high stress was because the weight of muck on the floor equivalent to $17 \mathrm{kPa}$ suppressed the stress induced damage.

One of the characteristics assigned to orebodies prone to seismicity is orebody dip. Steeply dipping orebodies are observed to be more amenable to seismicity than gentle dipping ones (Blake \& Hedley 2003). Hedley (1992) laments that, the reason often given for steeply dipping orebodies being rockburst-prone is the cumulative build-up of tangential stress in the wall rocks as depth is vague. A more plausible reason is the amount of shear stresses pillars are subjected to in these orebodies as depth increases. According to Suorineni et al. $(2011,2014)$ as shear stress in pillars increase the pillar core confinements drastically reduce and therefore making them more brittle and burst-prone. Excavation walls subjected to shear loading also 
exhibit elevated dynamic behaviour as exhibited in Figure 10. Further details on the latter can be found in Suorineni et al. (2014).

\subsection{Mining/excavation rate}

The issue of the benefits of mining rate visa-vie mechanised versus drill and blast remains controversial. Maloney and Kaiser (2010) have argued that because drill and blast often causes damage to the immediate excavation boundary, strainburst potential may be reduced. There is, however, a counter argument to this conclusion. Hedley (1992), Wiles (2016) and Salamon (1984) have all demonstrated that to manage strainbursts, rock must be excavated in small steps.

In the mist of the controversy, what is obvious is that mining rate can change rock behaviour. High mining rate results in high seismicity while low mining rate results in low probability of seismicity and can be used as seismicity management practice. This can be explained by comparing short-term to long-term rock strength or high loading rate to low loading rate rock strength. For the same rock sample under different strain rates the strength is different. Low strain rates give low strengths while high loading rates result in higher strengths. Lajtai and Bielus (1986) showed that for Lac du Bonnet granite, the strength at the International Society for Rock Mechanics (ISRM) suggested standard loading rate gives a strength of $225 \mathrm{MPa}$ that drops to $90-100 \mathrm{MPa}$ at a loading rate that results in 1,000 years of loading at $100 \%$ humidity and room temperature. At the latter loading rate, the rock will be aseismic. At high mining rates, there is no time allowed for stress redistribution and dissipation of energy and hence can result in an otherwise aseismic rock being seismic. Loading rate, in the sense described here, should be related to volume of material excavated at any one time rather than frequency of excavation. Volume of material removed at any one time differentiates long blast rounds from mechanised excavation that can be represented by infinite mining steps compared. Figure 9 shows the difference between these two forms of excavation in terms of energy dissipation and accumulation. While this remains controversial, mechanised excavation in several small steps appears to be more favourable to management of seismicity than single long or large blasts.

In Figure 9, $W_{k}$ is the seismic energy component that determines the extent of damage of rockbursts and depends on the number and size of the mining steps used to achieve the final size of an excavation. $U_{m}$ is stored strain energy and $W_{r}$ is releasable energy. The ratio $W_{k} / W_{r}$ is referred to as seismic efficiency (Hedley 1992). The figure therefore shows that if the excavation is made in one mining step (say a single blast), $62 \%$ of the releasable energy will be in the form of seismic energy and about $38 \%$ (red curve lowest point) as stored strain energy. However if the same size of excavation is made in a finite number of steps (say machine excavation) near zero percent of the releasable energy will be seismic energy while the rest (near 100\%) will be stored strain energy (red curve maximum point). Further details on elastic energy calculations based on seismological theories can be found in Hedley $(1992)$ and Salamon $(1983,1984)$.

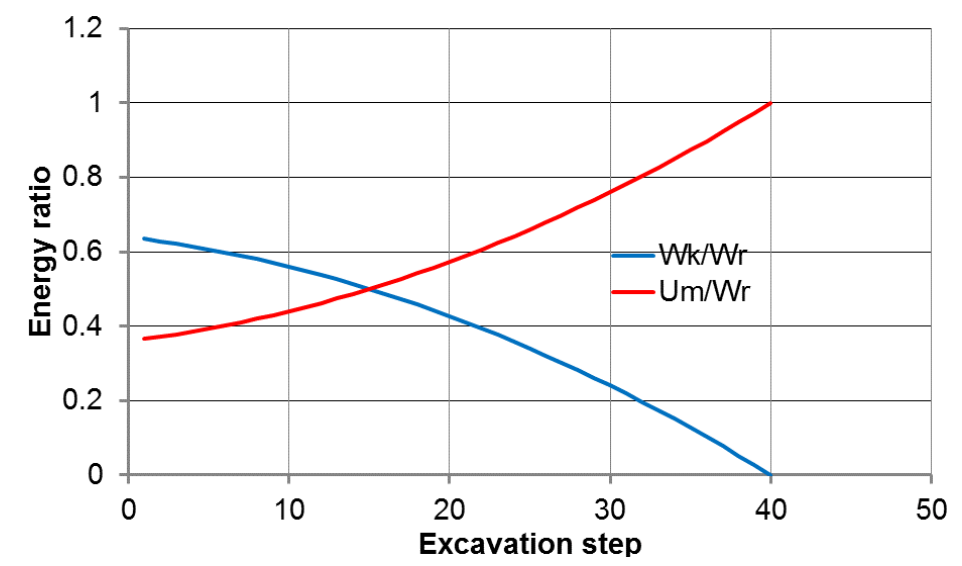

Figure 9 Comparison of excavation rates using blasting and mechanised excavation 


\subsection{Mining direction}

Suorineni et al. $(2011,2014)$ showed that when the major principal stress is not perpendicular to the orebody strike and is at an angle significantly oblique to the orebody strike, excavations and pillars are at elevated risk. The effect of oblique loading on pillars is discussed in Section 4.2.

Lac Shortt Mine employed several mining methods in an attempt to identify an optimised mining method. This discussion is based on the use of open stoping at the latter stages of the mine life. The relationship between the orebody strike and major principal stress is shown in Figure 10. The consequences of mining the orebody from west to east and from east to west are shown in Figures 10(a) and (b) respectively. Compared to mining from west to east (direction of major principal stress dip), where the damage is in the hanging wall, as evidenced the seismic data, mining from east to west (against dip of $\sigma_{1}$ ) results in degradation of the footwall. Note that if $\sigma_{1}$ were normal to the orebody strike, the high stress envelope will be contained in the orebody. Thus, knowing the major principal stress direction relative to orebody strike, mine planning and design can be optimally managed depending on the management strategy. This implies that prior knowledge to this behaviour will enable management or the geotechnical engineer to choose between protecting his footwall access by mining along dip of $\sigma_{1}$ or less dilution by mining against dip of $\sigma_{1}$ at the expense of the footwall infrastructure damage that might require regular rehabilitation. This is an opportunity cost situation.

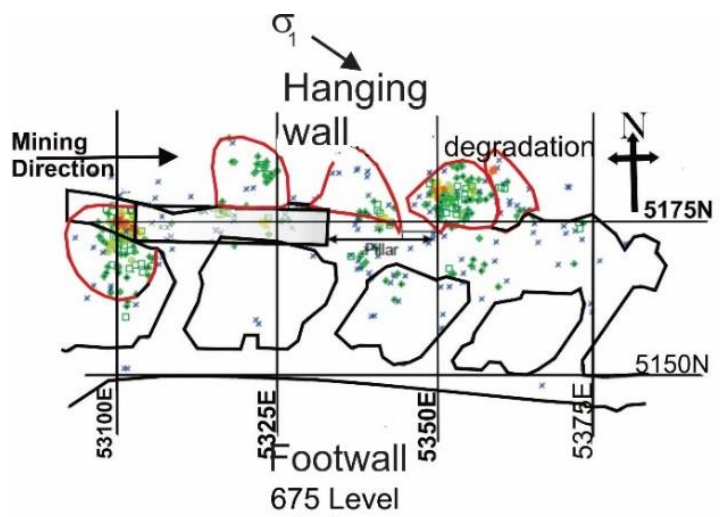

(a)

(a) Mining from west to east: damage in hanging wall

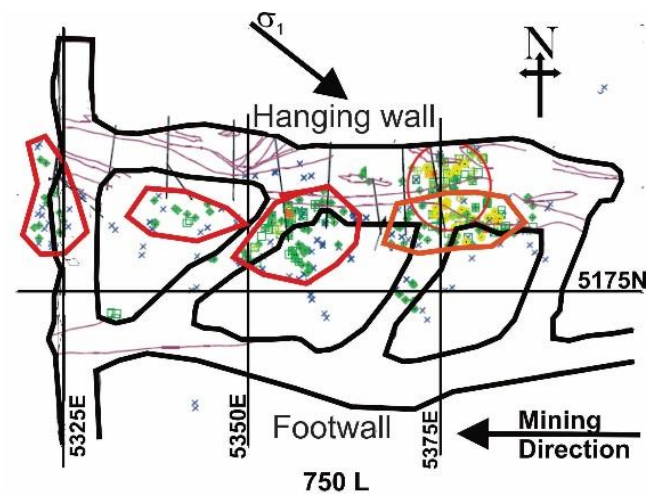

(b)

(b) Mining from east to west: damage in footwall

Figure 10 Consequences of mining direction when major principal stress is oblique to orebody strike (Suorineni et al. 2011)

\section{$4 \quad$ Case histories}

The following presents case histories of high stress conditions at depths that might be considered shallow, in hard rock mining conditions. At these depths, conventional thinking based on the issues raised above, would have shown no stress problems or seismicity should be expected.

\subsection{Creighton Mine}

Creighton Mine has been in operation for over a century and is a living in situ laboratory. Most mines in the Sudbury Basin learn how to deal with seismicity from Creighton Mine experience. Important mining methods have been introduced at Creighton Mine to optimise productivity while minimising rockbursts and include the vertical retreat mining (VRM) and chevron mining methods. The latter mining method is credited with pushing stresses outwards into the abutments while the former can be described as an advanced shrinkage mining method. This mine demonstrates several aspects of operational practices and the benefits of trial and error in optimising operational practices, ranging from what mining method is best, to identifying optimum ground support. The case example also shows how mining problems evolve with mine maturity (Figure 11). 
Figure 12 illustrates how ground support and other mine operational practices evolve through time, in a mine, to arrive at an optimal support system for management of seismicity.

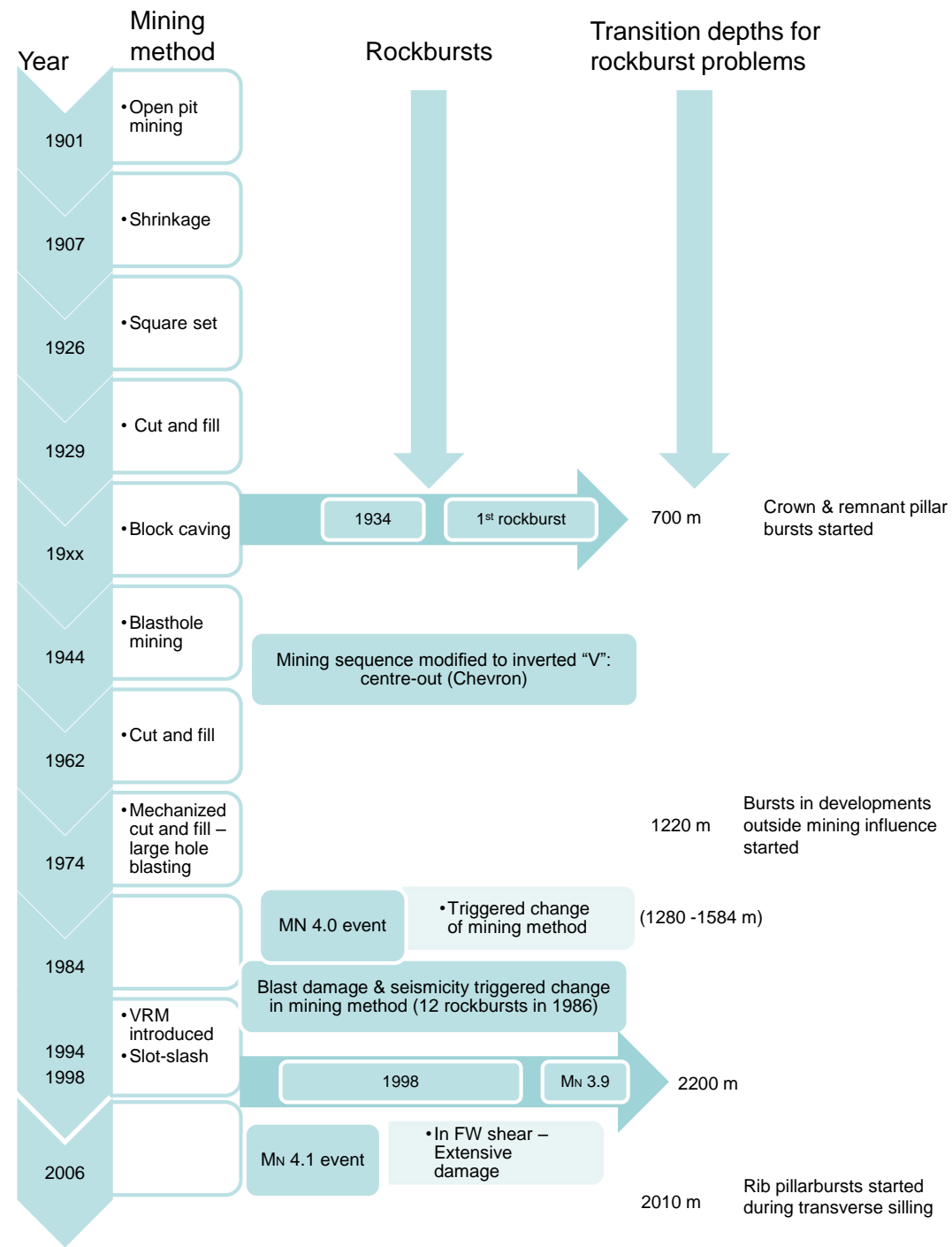

Figure 11 Evolution of mining practices at Creighton Mine (Vasak et al. 2010)
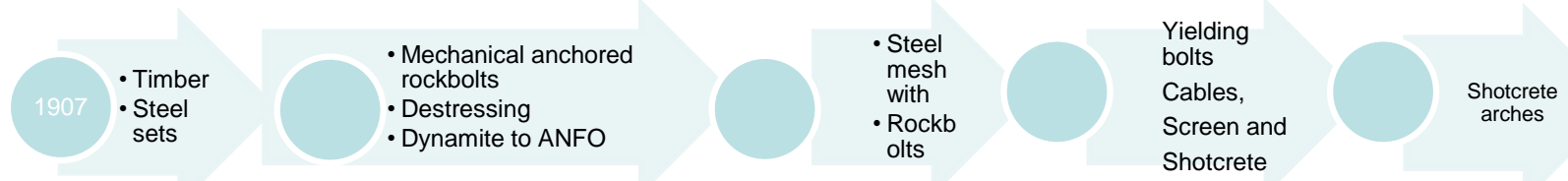

Figure 12 Evolution of Creighton Mine ground support and other operational practices with time (Vasak et al. 2010)

From the lessons learnt over the 100 years plus of mining at Creighton Mine, current mining method at the lower levels consists mainly of vertical retreat and slot-and-slash bulk mining with limited uppers mining of small hanging wall ore zones (Malek et al. 2008). The slot-slash mining method is a pillarless, top-down, centre-out mining sequence.

Malek et al. (2008) present current strategies for managing seismicity at Creighton Mine that are summarised here. Management of seismicity is achieved through a combination of seismic monitoring systems, de-stressing and innovative use of rockburst damage support systems (Figure 12). Properly sequenced stoping and backfilling also plays a significant role in the management of seismicity at the mine. 
The ground support system for Creighton Deep has continuously improved based on trials and analyses of the ground response and stress levels. Primary support systems have been improved with the development and implementation of the $46 \mathrm{~mm}$ friction sets (FS46) for wall bolting and the swellex bolts when mining under or beside sandfill. The use of swellex and super-swellex bolts for development under sandfill has improved the efficiency, reducing the cycle time and overall stability of the top sills (driven under sandfill). Enhanced support consists of a combination of cone bolts with zero-gauge straps or shotcrete arches. These two support systems have proven to be very effective in burst-prone conditions and around seismically-active geological structures, especially when installed during development or at the early stage of mining.

At depths below about 1,200 m, development at Creighton follows a strict perimeter and de-stress blasting technique to reduce the number of strain bursts in the development headings (Malek et al. 2008).

\subsection{Quirke Mine}

Suorineni et al. (2011) describe the case history of Quirke Mine at Elliot Lake near Sudbury in Ontario, Canada. This case history showed that by merely changing the orientation of rib pillars from down-dip to along-strike, in order to allow for trackless mining, domino pillar failure in the form of pillarburst ensued. Figure 13 shows the original pillars and the new pillars (in the yellow area). Note that the characteristic changed in the design is the orientation of long axis of the rib pillars with everything else remaining (pillar sizes and rock properties) the same. Numerical modelling back-analysis by Hedley et al. (1984) and recently by Suorineni et al. (2014) showed that the domino pillar failure was caused by shear loading due to the re-orientation of the pillars with their long axis along orebody strike, subjecting them to be being loaded at an angle relative to the major principal stress orientation as shown in Figure 13.

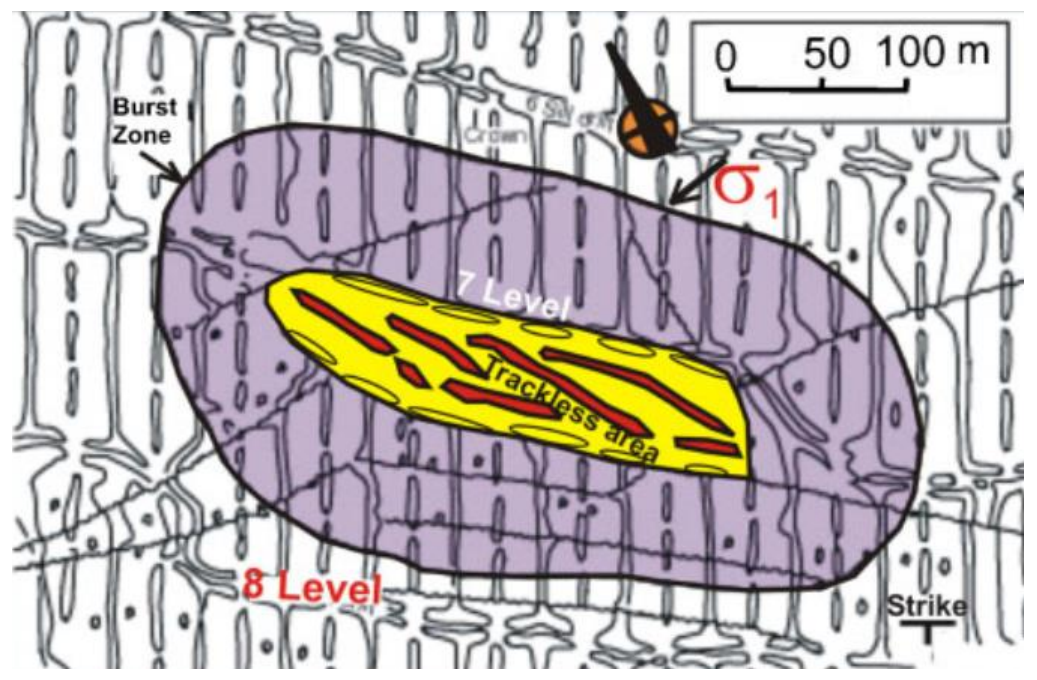

Figure 13 Realigned pillars for trackless mining caused domino pillarbursts (redrawn from Hedley 1992)

As shown in Section 3.1, Figure 8, the domino pillarburst at Quirke Mine can be attributed to loss of confinement following the reorientation of the pillars. The loss in confinement resulted in changing the pillar behaviour to being more brittle and weaker.

\subsection{Developments in sill pillars}

Another scenario that subjects mine excavations to high stress conditions even at shallow depths is drifting in sill pillars. Many instances of highly stressed conditions have been observed in drifts through sill pillars at shallow depths (Figure 14). In Figure 14(a) at Mine X, as shown in the hand sketch insert, in-drift is placed in between the sublevels. The new drift suffered severe stress-induced damage and required several rehabilitations. In Figure 14(b) at Mine Y, drifts with flat backs were used with the argument that depth below surface is shallow and hence use of arched back drifts was not warranted (Anon., pers. comm., 2011). This 
argument that the drift is developed at a shallow depth ignored the fact that the drift is developed in a highly stressed sill pillar whose width varied between 4 and $10 \mathrm{~m}$.
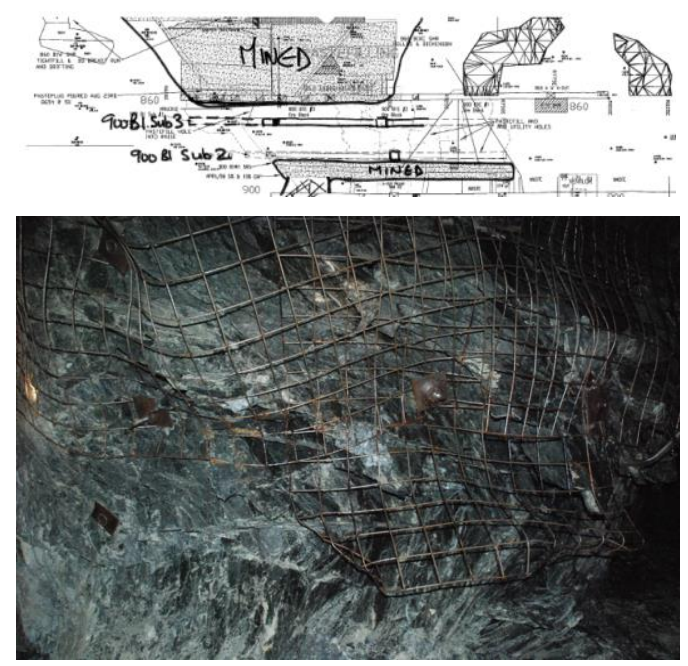

(a) Highly stressed drift $(2.5 \times 2.5 \mathrm{~m}$ high in a $22 \mathrm{~m}$ thick sill pillar at Mine $\mathrm{X}$. Drift located $7.5 \mathrm{~m}$ below top level. Depth below surface $<1,000 \mathrm{~m}$.

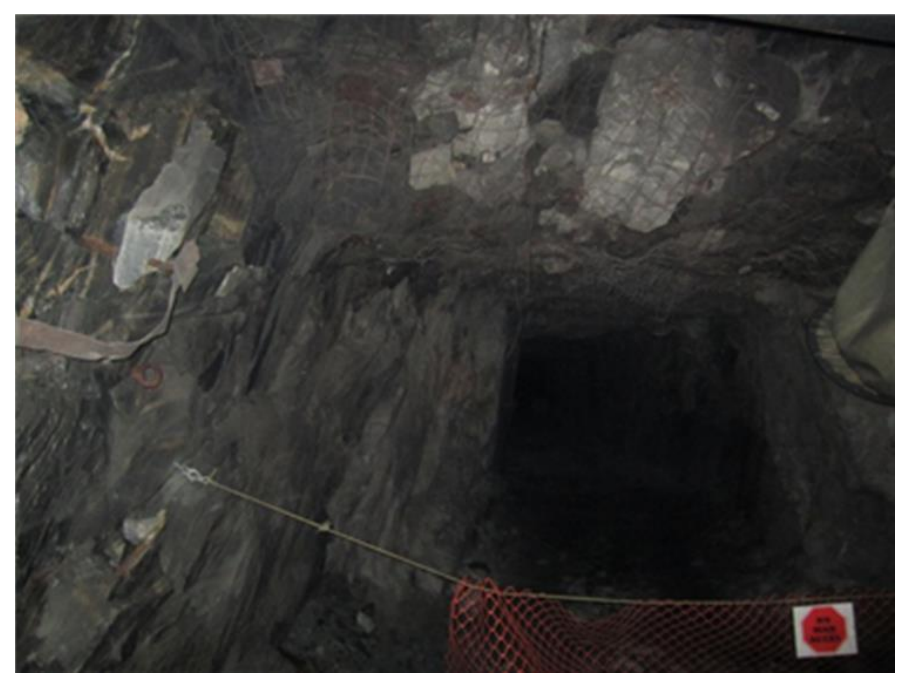

(b) Highly stressed $2.5 \times 3.5 \mathrm{~m}$ wide drift in sill pillar at Mine $Y$ showing stress fracturing. Sill pillar thickness varied from 4 to $10 \mathrm{~m}$ in places. Depth is $195 \mathrm{~m}$ below surface.

Figure 14 High stress conditions in drifts in sill pillars

\subsection{Diminishing pillar case example}

A relatively common mine planning and design flaw, often resulting in the creation of high stress conditions, is operational practices resulting in what is known as diminishing pillar scenarios. Diminishing pillars can result from mining sequences resulting in two mining fronts moving towards each other as shown in Figure 4.

Turner and Beck (2002) describe a real case example of such a practice (Figure 15) that is summarised here. Even though in this case example Turner and Beck (2002) did not provide the geotechnical characteristics of the mine environment, the mine presents a good example of how operational practices can sometimes jeopardise mining efficiency by misjudging the 'high stress condition' definition. The example mine shown was mining back on each level towards a centrally located decline using an uphole retreat method. This is a method often associated with intense seismicity in susceptible mines (Turner \& Beck 2002). The figure shows the $50^{\text {th }}$ (black) and $90^{\text {th }}$ (grey) percentiles and the largest recorded event for each month in the mine, for the period including the flurry and then a subsequent sequence change. In this example Turner and Beck (2002) stated that the central pillar was left unmined on the levels affected by seismicity as it was unmineable due to the intense seismic related fracturing.

Following a flurry of seismic activity, and after a significant reduction in the remaining mineral resource, the mine design limitations were assessed and a continuous, pillarless sequence resulted in improved ground conditions in access development and a reduced seismic hazard for all areas.

In these cases, at some critical distance between the two mining fronts, the pillar gets overstressed and becomes seismically-active as is evidenced in Figure 15. Diminishing pillar cases can create high stress situations at any depth. 


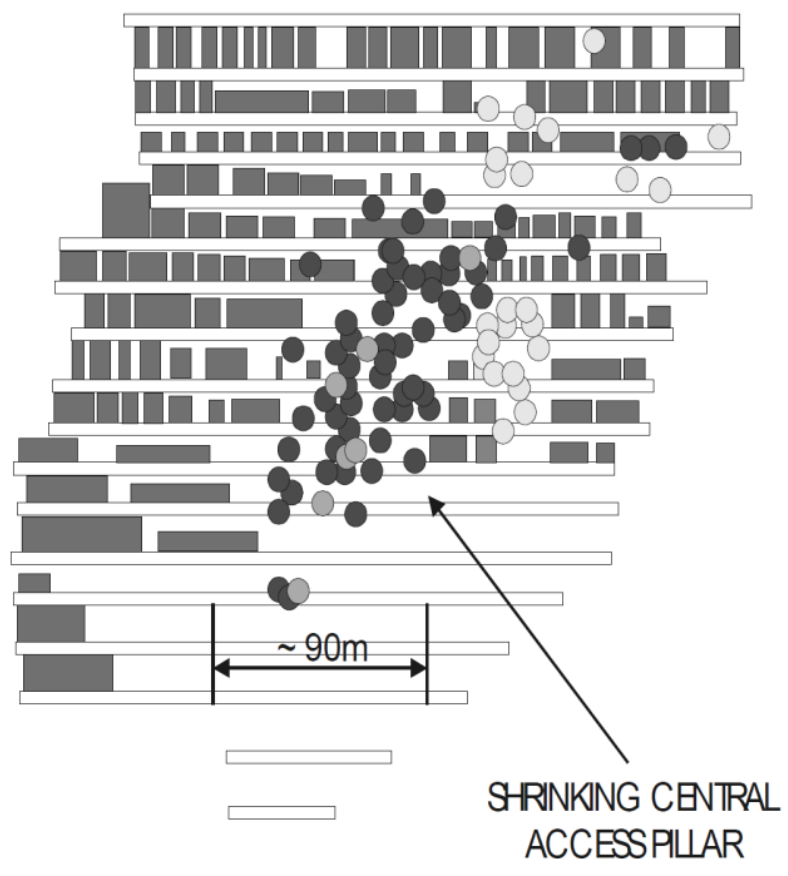

Figure 15 Longitudinal section of a mine showing a diminishing pillar resulting in seismicity (from Turner $\&$ Beck 2002). Mining from both left and right resulted in a diminishing pillar.

The diminishing pillar scenario can also be likened to mining towards a fault. Mining towards a fault is well-known to not be a recommended mining approach. Figure 16 compares two scenarios, with one being mining towards a fault and the second mining away from the fault. The figure shows energy build-up that could lead to large magnitude events when mining towards a fault.

Another scenario associated with mining close to faults is the reduction in normal stress (confinement) that eventually results in fault slip due to excess shear stress to cause rockbursts and seismicity.

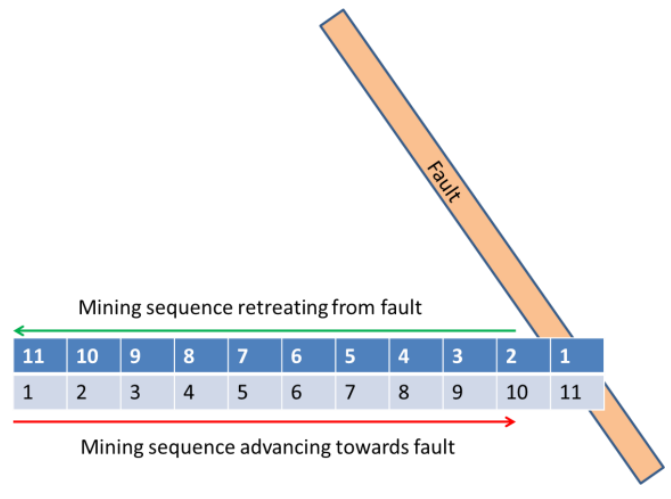

(a) Mining sequence options in the presence of a fault

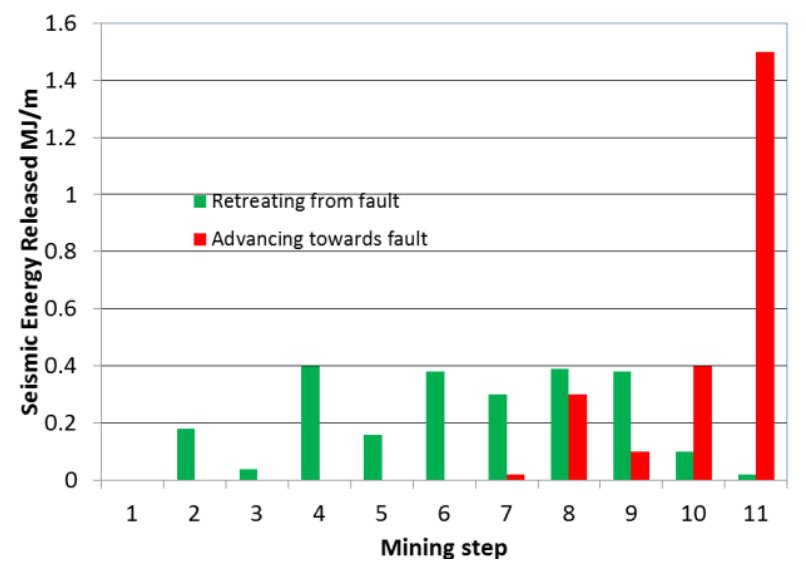

(b) Comparison of energy released for mining towards and retreating from a fault

Figure 16 Effect of mining options in the presence of a fault with respect to management of seismicity (redrawn from Hedley 1992) 


\section{$5 \quad$ Concluding remarks}

The subject of deep and high stress is important in mining. The theme of this conference 'deep and high stress mining' is a testament to this view. Despite this significance of deep and high stress mining, myths remain as to what is actually 'deep and high stress'. This paper has attempted to throw more light on the subject of 'deep and high stress' to clarify some of the most misunderstood concepts. Understanding these concepts is important for safe mine planning and design practices. The case examples provided from the literature provide practical situations to guide mine planning and design engineers. The following conclusions are arrived at in the paper.

The use of the term 'deep and high stress' is misleading and can be confusing. Depth is not the only factor that contributes to high stress. Operational/mining practices and rock and material strength can result in high stress conditions where they are least expected. High stress conditions can be encountered at shallow depths and even in quarries or open pit mines.

The discussion of high stress should include any actions that change the material/rock behaviour. These actions include mining sequence, mining rate and mining direction relative to orientations of the major principal stress direction. Orebodies in shear exhibit high stress conditions where that is least expected. Similarly, change in temperature and or confinement can result in high stress conditions at relatively shallow depths.

High stress should be related to material/rock strength. For a given stress level, weak and strong materials may exhibit different behaviours with respect to seismicity.

In situ stress measurement methods and interpretation of the results need to be revolutionised to increase confidence in stress measurement results and reduce the uncertainties often incurred. Current stress measurements often produce results with significant scatter to pose challenge to design engineers as to what values to use. Stress orientation, apart from its magnitude, is equally important in identifying seismically-active conditions as illustrated in some of the case histories.

\section{References}

Amadei, B \& Stephansson, O 1997, Rock Stress and Its Measurement, Springer-Verlag, Tokyo, pp. 490.

Bieniawski, ZT 1989, Engineering Rock Mass Classifications, John Wiley \& Sons, New York, pp. 251.

Blake, W \& Hedley, DGF 2003, Rockbursts: case studies from North American hard rock mines, Society for Mining, Metallurgy and Exploration, Englewood, pp. 121.

Coates, DF 1964, 'Some cases of residual stress effects in engineering works', in WR Judd (ed), 'State of Stress in the Earth's Crust', Elsevier, New York, pp. 679-688.

Diering, DH 2000, 'Mining at ultra depths in the 21st century', Canadian Institute of Mining, Metallurgy and Petroleum Bulletin, vol. 93, no. 1,036, pp. 279-288.

Fettweis, GB 1979, World Coal Resources, Elsevier Scientific Publishing, New York, pp. 415.

Grabinsky, MW, Curran, JH \& Bawden, WF 1997, 'Interaction between stress, mine geometry and rock mass behaviour at a Canadian shield mine', Canadian Institute of Mining, Metallurgy and Petroleum Bulletin, vol. 90, no. 1,013. pp. 45-51.

Hawkes, I \& Mellor, M 1970, 'Uniaxial testing in rock mechanics laboratories', Engineering Geology, vol. 4, pp. $177-285$.

Hedley, DGF, Roxburgh, JW \& Muppalaneni, SN 1984, 'A case history of rockbursts at Elliot Lake', in CO Brawner (ed), Proceedings of the Second International Conference on Stability in Underground Mining, American Institute of Mining, Metallurgical and Petroleum Engineers Inc, Englewood, pp. 210-234.

Hedley, DGF 1992, Rockburst Handbook for Ontario Hard Rock Mines, CANMET Special Report SP92-1E, Energy, Mines and Resources Canada, Canada Center for Mineral and Energy Technology, Quebec, pp. 305.

Hoek, E 1994, 'The challenge of input data for rock engineering. Letter to the editor', ISRM News Journal, vol. 2, no. 2, pp. 23-24.

Lajtai, E \& Bielus, L 1986, 'Stress corrosion cracking of la du Bonnet granite in tension and compression', Rock Mechanics and Rock Engineering, vol. 19, pp. 71-87.

Lee, M 2011, Ok Tedi Mining Ltd. - Review of stresses, report submitted to Ok Tedi mine, 9 May, AMC Consultants Pty Ltd., Perth.

Lee, MF, Baczynski, NRP, Mills, KW, de Bruyn, Al \& Mollison, L 2014, 'Rock stresses at Ok Tedi, Papua New Guinea', in PC Hagan \& S Saydam (eds), Proceedings of AusRock 2014: Third Australasian Ground Control in Mining Conference, Australasian Institute of Mining and Metallurgy, Carlton South, pp. 337-345.

Luppens, JA, Rohrbacher, TJ, Osmonson, LM \& Carter, MD 2009, 'Coal resource availability, recoverability, and economic evaluations in the United States-A summary', Chapter D, in BS Pierce \& KO Dennen (eds), The National Coal Resource Assessment Overview, pp. 21. 
Malek, F, Trifu, C, Suorineni, FT, Espley, S \& Yao, M 2008, 'Management of high stress and seismicity at Vale Inco Creighton mine', Proceedings of the 42 ${ }^{\text {nd }}$ U.S. Rock Mechanics Symposium, American Rock Mechanics Association, Alexandria, pp. 8.

Maloney, S \& Kaiser, PK 2010, 'Evaluation of strainburst potential associated with excavation damage zone due to excavation method', in A Ackerman \& R Slack (eds), Proceedings of the 2010 Maintenance Engineering and Mine Operators Conference, Canadian Institute of Mining, Metallurgy and Petroleum, Sudbury, pp. 8.

Martin, CD 1997, 'Seventeenth Canadian Geotechnical Colloquium: The effect of cohesion loss and stress path on brittle rock strength', Canadian Geotechnical Journal, vol. 34, no. 5, pp. 698-725.

Martin, CD, Christiansson, R \& Soderhall, J 2001, Rock stability considerations for siting and constructing a KBS-3 repository: Based on experiences from Äspö HRL, AECL's URL, tunnelling and mining, technical report, TR-01-38, pp. 94.

Mills, K 2010, In situ stress measurements in Ok Tedi drainage tunnel, Report \#OTML 3562, submitted to Ok Tedi Mining Ltd., Strata Control Technology Operations Pty Ltd., 17 December.

Power, WI, Edgoose, JJ \& Enever, JR 1991, In situ stresses in the Ok Tedi Mine region, Western province, Papua New Guinea, Internal Report, New series \#57, CSIRO Division of Geomechanics, Institute of Minerals, Energy and Construction, July.

Read, RS, Martino, JB, Dzik, EJ, Oliver, S, Fall, S \& Young, R 1997, Analysis and interpretation of AECLs heated failure tests, Technical Report, 06819-Rep-012000-0070 R00, Toronto.

Salamon, MDG 1983, 'Rockburst hazard and the fight for its alleviation in South African Gold Mines', in IW Farmer (ed), Proceedings of Rockbursts: Prediction and Control, Institution of Mining and Metallurgy, London, pp. 11-36.

Salamon, MDG, 1984, 'Energy considerations in rock mechanics: Fundamental results', Journal of the South African Institute of Mining and Metallurgy, vol. 84, no. 8, pp. 223-246.

Stacey, TR \& Wesseloo, J 1998, 'In situ stresses in mining areas in South Africa', Journal of the South African Institute of Mining and Metallurgy, pp. 365-368.

Suorineni, FT 2013, The Geomechanics Challenges of Contemporary Deep Mining: Technology as the Pathway to Increased Safety and Productivity, Kenneth Finlay Memorial Lecture, The University of New South Wales, Sydney, New South Wales.

Suorineni, FT 2015, 'In-situ stress measurement errors - Implications in mine planning, design, and performance', in C Musingwini \& C Singhal (eds), Proceedings of MPES 2015 - Smart Innovation in Mining, Southern African Institute of Mining and Metallurgy, Johannesburg, pp. 215-227.

Suorineni, FT \& Malek, F 2014, 'The Sudbury Basin stress tensor: myth or reality', in M Hudyma \& Y Potvin (eds), Proceedings of the Seventh International Conference on Deep and High Stress Mining, Australian Centre for Geomechanics, Perth, pp. 615-625.

Suorineni, FT, Mgumbwa, JJ, Kaiser, PK \& Thibodeau, D 2011, 'Mining of orebodies under shear loading Part 1 - case histories', Transactions of the Institution of Mining and Metallurgy (Section A: Mining Technology), vol. 120, no. 3, pp. 138-147.

Suorineni, FT, Mgumbwa, JJ, Kaiser, PK \& Thibodeau, D 2014, 'Mining of orebodies under shear loading part 2 - failure modes and mechanisms', Mining Technology, vol. 123, no. 4, pp. 240-249.

Suorineni, FT \& Maloney, S 2009, Geomechanics Study for the Hoyle Pond Mine at Depth, reported submitted to Goldcorps Hoyle Pond Mine, pp. 78.

Swan, G, Kazakidis, V, Brummer, RK \& Graham, C 2005, 'Deep mining research: implementing technology to manage risk', Proceedings of the Maintenance, Engineering and Reliability/Mine Operators Conference (MEMO 2005), Canadian Institute of Mining, Metallurgy and Petroleum, Westmount, pp. 12.

Terzaghi, K \& Richart, FE 1952, 'Stresses in rock about cavities', Geotechnique, vol. 3, pp. 57-90.

Turner, M \& Beck, D, 2002 'Monitoring the onset of seismicity', in Y Potvin (ed), Proceedings of the Fourth International Seminar on Deep and High Stress Mining, Australian Centre for Geomechanics, Perth, pp. 22.

Vasak, P, Suorineni, FT \& Maloney, S 2011, Mining-induced seismic periodicity and major rockburst occurrences at Creighton mine: Phase 1 - Temporal seismic trends, report submitted to Creighton Mine, Sudbury, pp. 20.

Villaescusa, E \& Machuca, L 2007, Stress Measurements from Oriented Core Using the Acoustic Emission Method, Ok Tedi standalone report submitted July, Western Australia School of Mines, Curtin University of Technology, Kalgoorlie.

Wiles, T 2016, Map3D Manual, viewed 24 January 2017, www.map3d.com

White, WS 1946, Rockbursts in the granite quarries at Barre, Vermont, Circular 13, US Geological Survey, San Francisco, California.

Winkler, EM 1975, 'Stone: properties, durability in man's environment', Applied Mineralogy, vol. 4, Springer-Verlag, New York, pp. 230. 